\title{
Celebrity worship dan Impulsive buying pada Penggemar KPOP Idol
}

\author{
Nadine Denita Asrie ${ }^{1}$, Dian Misrawati ${ }^{*}$ ) \\ 1,2*) Fakultas Psikologi Universitas Mercu Buana \\ e-mail : ${ }^{1}$ nadine.dhenita@gmail.com ${ }^{*}$ dian.misrawati@mercubuana.ac.id
}

\begin{abstract}
This study aimed to determined and explained the impact of celebrity worship on impulsive buying on idol merchandise, in this study specifically on BTS merchandise. A sample of 303 respondents were teenagers aged $13-21$ years who loved the idol group, BTS. The sampling technique uses a snowball-sampling technique. The measuring instrument used is The Impulse Buying Tendency which has been modified with the cronbach alpha reliability coefficient of 0.862 and Celebrity Attitude Scale which has been modified with the cronbach alpha reliability coefficient of 0.901 . The result showed that celebrity worship had an effect on impulsive buying on BTS merchandise with an $R^{2}$ value of 0.278 . The results of the study that celebrity worship has an effect on impulsive buying on BTS merchandise can be seen from the tcount of 10.765 more than 1.967 with a significance value $p$ less than 0.005. The conclusion is celebrity worship has an impact on impulsive buying on BTS merchandise for teenagers who are fans of BTS. Further research can be carried out on random idol groups other than $B T S$, so it can be seen whether celebrity worship really affects impulsive buying of idol merchandise in general.
\end{abstract}

Keywords: Celebrity worship, Impulsive buying, KPOP

Abstrak. Penelitian ini bertujuan untuk mengetahui dan menjelaskan pengaruh celebrity worship terhadap impulsive buying pada merchandise idola, dalam penelitian ini khususnya merchandise BTS. Sampel sebanyak 303 responden merupakan remaja dengan rentang usia 12 - 20 tahun yang menggemari grup idola BTS. Teknik pengambilan sampel menggunakan teknik snowball-sampling. Alat ukur yang digunakan adalah The Impulse Buying Tendency yang telah dimodifikasi dengan koefisien reliabilitas cronbach alpha sebesar 0,862 dan Celebrity Attitude Scale yang dimodifikasi dengan koefisien reliabilitas cronbach alpha sebesar 0,901. Hasil penelitian menunjukan bahwa celebrity worship berpengaruh terhadap impulsive buying pada merchandise idola dengan nilai $R^{2}$ sebesar 0,278. Hasil penelitian bahwa celebrity worship berpengaruh terhadap impulsive buying pada merchandise idola dapat dilihat dari thitung sebesar 10,765 lebih dari 1,967 dengan nilai signifikansi $p$ kurang dari 0,005. Dengan demikian dapat disimpulkan bahwa celebrity worship memiliki pengaruh terhadap impulsive buying merchandise BTS pada remaja penggemar grup idola BTS. Penelitian selanjutnya dapat dilakukan pada random grup idola lain selain BTS, sehingga dapat dilihat apakah celebrity worship benar mempengaruhi impulsive buying terhadap merchandise idola secara umum.

Kata Kunci: Celebrity worship, Pembelian Impulsif, KPOP

\section{Pendahuluan}

Manusia sebagai makhluk homo economicus tidak bisa melepaskan diri dari aktivitas pertukaran antar sesama manusia yang memberikan keuntungan bagi kelangsungan hidupnya, melalui transaksi perdagangan atau jual beli. Pembelian yang dilakukan oleh manusia biasanya didasarkan pada faktor kebutuhan terhadap produk atau jasa yang ditawarkan, namun perkembangan trend jual beli dalam perdagangan pada era sekarang ini telah melalui perubahan dan pergeseran. Orang-orang tidak lagi 
melakukan pembelian atas dasar kebutuhan (need) saja dan mulai disebabkan karena dorongan keinginan (want) semata. Pada saat seseorang memiliki keinginan yang kuat untuk membeli sebuah produk atau jasa, dengan cepat pertukaran pun terjadi, tanpa melakukan pertimbangan akan kebutuhan maupun pertimbangan lainnya (Pemayun \& Ekawati, 2016). Artinya, keputusan untuk membeli yang dilakukan individu tersebut bukan didasarkan atas perencanaan yang melibatkan proses berfikir logis dan rasional, melainkan bentuk pembelian yang lebih bersifat mendadak dan tiba-tiba berdasarkan keinginan yang bergejolak pada saat itu.

Bentuk pembelian yang tidak direncanakan, tidak rasional, dan didorong oleh faktor emosional yang kuat ini merupakan istilah yang sering kali digambarkan sebagai impulsive buying (Verplanken \& Herabadi, 2001). Pembelian secara mendadak dan tidak terencana merupakan fenomena yang semakin marak terjadi di kehidupan masyarakat masa kini, ditambah dengan perkembangan media e-commerce yang semakin mempermudah aktivitas belanja. Nielsen, sebuah badan usaha yang bergerak dalam mempelajari perilaku konsumen, telah melakukan Survey di tiga kota besar Indonesia, yaitu Jakarta, Bandung dan Surabaya pada tahun 2013. Hasil survey tersebut menunjukkan bahwa sekitar 85\% orang pernah membeli sesuatu dengan tidak terencana baik dalam frekuensi selalu maupun kadang-kadang, sementara hanya $15 \%$ orang yang melakukan pembelian sesuai dengan perencanaan yang telah dilakukan dan tidak melakukan pembelian di luar perencanaan.

Beberapa faktor dapat mempengaruhi tindakan pembelian impulsif yang dilakukan seseorang. Verplanken \& Herabadi (2001) menjelaskan bahwa faktor internal dan eksternal dapat mempengaruhi kecenderungan seseorang terhadap pembelian impulsif, misalnya jenis kelamin atau usia. Sementara faktor eksternal berkaitan dengan hal-hal yang terjadi di sekitar individu. Berdasarkan penelitian yang dilakukan oleh Chyang, Yau, \& Han (2008) diketahui bahwa perasaan mendalam seseorang terhadap idola juga dapat mempengaruhi kecenderungannya untuk melakukan pembelian secara impulsif. Perasaan cinta yang mendalam selebriti yang diidolakan dapat melahirkan sebuah keyakinan dan pemahaman berupa hubungan, kesetiaan, dan bahkan pengabdian terhadap sang idola. Kecintaan mendalam yang dirasakan penggemar tersebut dapat mendorongnya untuk rela melakukan berbagai hal untuk idolanya, meskipun hal tersebut dapat menghabiskan uang, waktu dan tenaganya (Seregina, Koivisto, \& Matilla, 2011).

Salah satu aspek yang terdapat dalam konsep celebrity worship berkaitan dengan intense personal feeling (perasaan pribadi yang intens). Aspek ini menggambarkan sikap penggemar yang obsesif dan cenderung impulsif terhadap hal-hal yang berkaitan dengan selebriti yang mereka idolakan. Penggemar ini kemudian menjadi terobsesi dengan figure idola tersebut dan tertarik dengan kehidupan pribadi dan hal-hal lainnya yang berkaitan dengan selebriti idola tersebut. Fenomena ini merupakan kejadian yang telah berlangsung sejak lama, namun perubahan besar terjadi dalam satu dekade terakhir, dimana idola yang menjadi pusat perhatian penggemar yang biasanya berasal dari Eropa ataupun Amerika Serikat kini berubah arah ke Asia, terutama didukung dengan adanya fenomena korean wave.

Korean wave merupakan istilah yang awalnya digunakan oleh masyarakat Korea Selatan untuk menggambarkan perkembangan pesat yang terjadi pada budaya Korea yang tersebar luas ke seluruh penjuru dunia, Eropa, Amerika dan termasuk pula di Indonesia. Menariknya, penyebaran kebudayaan tersebut bukan disebabkan karena promosi pemerintah Korea Selatan, melainkan berkembang melalui karya seni di bidang hiburan (entertainment), seperti drama, film, variety show atau bahkan musik. Sektor drama dan musik memberikan peran paling besar dalam penyebaran korean wave. Melalui bidang akting dan musik tersebut bermunculan idola-idola yang digemari oleh banyak orang yang tersebar hampir di seluruh dunia.

Pada sektor musik, hadirnya grup musik yang beranggotakan anak-anak muda menjadi faktor pendorong terbesar yang makin menyebarkan korean wave di seluruh penjuru duni, termasuk di Indonesia. Salah satu grup band yang paling populer saat ini adalah Bangtan Sonyeondan atau Beyond 
The Scenes atau yang lebih dikenal dengan BTS. Boyband yang memulai debut pada tahun 2013 ini, terus meningkatkan popularitasnya di Korea melalui video musik, iklan dan acara varietas. Pada tahun 2017 BTS memulai debut internasionalnya dan terus melejit sampai saat ini menggantikan boyband pada generasi sebelumnya, seperti super junior, bigbang, atau 2pm. BTS juga berhasil bersaing dengan rival satu generasinya, seperti EXO, Seventeen, BTOB, dan grup lainnya. Hal ini terlihat dari survey dan rangking yang dilakukan oleh situs pecinta budaya korea, seperti allkpop.com atau soompi.com. Berdasarkan jumlah penggemar yang tergabung ke dalam fancafe (sama seperti komunitas penggemar), BTS selalu menduduki posisi pertama sejak tahun 2018 hingga 2020 sebagai grup boyband yang memiliki anggota penggembar terbanyak (Dewi, 2020).

BTS sebagai grup boyband ataupun para anggotanya sebagai personal memberikan pengaruh yang cukup besar terhadap para penggemarnya, termasuk dalam hal perilaku membeli suatu produk. Berdasarkan wawancara yang dilakukan kepada penggemar KPop idol yang tergabung dalam komunitas BTS Army mengungkapkan bahwa mereka dengan cepat memutuskan untuk membeli halhal yang berkaitan dengan grup idola maupun personel yang mereka idola. Jarang sekali para penggemar yang memiliki pertimbangan kebutuhan, harga maupun kualitas ketika menginginkan produk yang berkaitan dengan idola mereka. Pembelian yang marak terjadi berupa produk merchandise, produk yang dipromosikan atau produk yang digunakan secara pribadi oleh idola, maupun tiket konser idola. Pembelian secara cepat dan mendadak terhadap produk-produk yang berkaitan dengan idola semakin marak terjadi dengan menjamurnya toko-toko yang berbasis produk idola, baik yang hadir secara off line maupun on line. Mereka tetap memiliki dorongan yang besar untuk melakukan pembelian, meskipun dengan harga yang mahal, dan tak jarang menuntut pengorbanan yang besar dari mereka.

Menurut Mowen \& Minor (2002), individu yang memiliki kecenderungan melakukan pembelian secara spontan akan memutuskan untuk segera membeli produk yang telah mencuri perhatiannya tanpa mau berpikir ulang. Mereka memiliki perasaan yang kuat dan positif terhadap produk yang akan dibeli dan mendorongnya untuk membeli tanpa memikirkan atau mempertimbangkan konsekuensi yang akan diperoleh karena pembelian tersebut. Perasaan positif yang kuat terhadap hal-hal yang berkaitan dengan idola yang mendorong seseorang untuk melakukan berbagai hal terkait dengan idolanya disebut sebagai celebrity worship (Maltby, dkk., 2004).

Penggemar yang mengembangkan kebiasaan untuk melihat, mendengar, membaca dan mempelajari tentang kehidupan selebriti idola mereka kemudian dapat terobsesi pada selebriti idola tersebut dan tertarik dengan kehidupan pribadi selebriti. Perasaan obsesi yang berlebihan dapat mengarah pada tumbuhnya empati, identifikasi, imitasi dan asosiasi untuk menjadi sama dan merasa dekat dengan para idola tersebut. Hal ini dapat mendorong para penggemar untuk meniru idola mereka dan memiliki barang-barang yang sama dengan idola.

Identifikasi dan imitasi yang dialami penggemar mengarahkan mereka untuk melakukan pembelian-pembelian terhadap merchandise maupun barang-barang pribadi yang digunakan oleh selebriti idola berdasarkan dorongan emosional yang berlebihan dan mengesampingkan pertimbangan rasional mengenai kebutuhan dan kelayakan suatu produk yang dibeli. Pembelian yang demikian disebut dengan istilah impulsive buying. Penelitian ini bertujuan untuk mengetahui dan menjelaskan pengaruh celebrity worship terhadap impulsive buying pada merchandise idola, dalam penelitian ini khususnya merchandise BTS.

\section{Metode}

\section{Partisipan dan prosedur}

Subjek penelitian merupakan anggota komunitas fan base Grup KPOP BTS yang disebut dengan ARMY di wilayah Jakarta. Sampel yang dilibatkan dalam penelitian adalah 303 remaja yang berusia 13- 
21 tahun yang berdomisili di DKI Jakarta dan telah bergabung sebagai anggota komunitas minimal selama 1 tahun. Data dikumpulkan dengan menggunakan online form melalui platform google form, dengan teknik convenience sampling. On line form terdiri dari tiga bagian, yaitu bagian identitas dan data demografi, kuesioner celebrity worship dan kuesioner impulsive buying.

\section{Instrumen}

Alat ukur yang digunakan dalam penelitian ini adalah kuesioner The Impulsive Buying Tendency Scale dari Verplanken \& Herabadi (2001) yang telah diadaptasi ke bahasa Indonesia oleh Handayani (2018). Tim peneliti kemudian melakukan modifikasi alat ukur dengan menyesuaikan item-item dengan relevansi pembelian terhadap merchandise BTS. Kuesioner modifikasi terdiri dari dua aspek dalam 13 item yang telah lulus uji coba dengan koefisien reliabilitas sebesar $\alpha=0,862$. Kuesioner kedua adalah kuesioner Celebrity Attitude Scale dari Maltby dan McCutcheon (2004) yang telah dimodifikasi oleh Fajariyani (2018), dan peneliti kemudian melakukan uji coba ulang terhadap reliabilitas kuesioner dalam penelitian ini. Alat ukur ini terdiri dari tiga aspek yang diwakili oleh 25 item yang telah lolos tahap uji coba, dengan koefisien reliabilitas $\alpha=0,901$. Kedua alat ukur menggunakan bentuk skala Likert yang terdiri atas empat pilihan jawaban, yaitu Sangat Setuju (SS), Setuju (S), Kurang Setuju (KS), dan Tidak Setuju (TS).

\section{Analisis}

Analisis data dilakukan dengan bantuan SPSS for windows versi 20. Adapun teknik analisis yang digunakan adalah uji regresi linear sederhana, dengan sebelumnya melakukan uji asumsi klasik terlebih dahulu, seperti uji normalitas dan uji linearitas. Analisis tambahan dilakukan dengan membandingkan gambaran impulsive buying dan celebrity worship pada kelompok subjek yang berbeda.

\section{Hasil Penelitian}

Distribusi responden dikelompokkan berdasarkan usia dan durasi lamanya menggemari grup idola BTS dapat dilihat pada tabel 1 dan 2 berikut ini:

Tabel 1 Gambaran Responden berdasarkan Tahap Perkembangan dan Durasi menggemari Idola (N=303)

\begin{tabular}{lcc}
\hline \multicolumn{1}{c}{ Variabel } & Jumlah & Persentase (\%) \\
\hline Usia & & 32 \\
\hline $13-15$ tahun & 96 & 38 \\
\hline $16-18$ tahun & 115 & 30 \\
\hline $19-21$ tahun & 92 & \\
\hline Durasi Menggemari BTS & & 56 \\
\hline $1-2$ tahun & 170 & 37 \\
\hline $3-4$ tahun & 113 & 7 \\
\hline dari 5 tahun & 20 & \\
\hline
\end{tabular}

Pengelompokan usia subjek didasarkan pada teori perkembangan psikososial dari Erikson (dalam Papalia, 2008) yang membagi 3 tahapan perkembangan remaja, yaitu remaja awal (13-15 tahun), remaja tengah (16-18 tahun) dan remaja akhir (19-21 tahun). Berdasarkan tabel 1 di atas dapat diketahui bahwa jumlah subjek terbanyak berasal dari usia remaja tengah yaitu sebesar 38\% dari total keseluruhan subjek, namun demikian jika dibandingkan dengan presentase jumlah kelompok usia remaja yang lain, penyebarannya cukup berimbang, yaitu berkisar sepertiga dari jumlah total keseluruhan subjek penelitian (tabel 1). 
Sebagian besar subjek merupakan penggemar yang baru bergabung di fan base ARMY, yaitu sebesar $56 \%$. Sementara itu, kelompok terkecil berasal dari penggemar yang sudah 5 tahun atau lebih mengidolakan BTS, yaitu sebesar 7\%. Hal ini dipengaruhi oleh perjalanan BTS sebagai grup idola yang baru memulai debutnya pada tahun 2013 dan debut internasional dimulai pada tahun 2017 (tabel 1).

Tabel 2 Hasil Uji Normalitas dan Linearitas

\begin{tabular}{lllll}
\hline Variabel & Sig. KS & Keterangan & Sig. ToL & Keterangan \\
\hline $\begin{array}{l}\text { Impulsive Buying } \\
\text { Celebrity Worship }\end{array}$ & 0,053 & Normal & 0,000 & \multirow{2}{*}{ Linear } \\
\hline
\end{tabular}

Hasil uji normalitas dengan Kolmogorov Smirnov (KS) dan uji linearitas dengan Test of Linearity (ToL) dapat dilihat pada tabel 2. Dapat disimpulkan bahwa skor responden pada variabel impulsive buying dan celebrity worship berdistribusi normal $(p>0,05)$, sehingga pengujian hipotesis dapat dilakukan dengan teknik statistik parametrik. Hasil test of linearity menunjukkan bahwa Skor impulsive buying linear dengan celebrity worship ( $\mathrm{p} \varangle 0,05)$, sehingga uji korelasi dan uji regresi dapat dilakukan.

Tabel 3 Hasil Uji Korelasi

\begin{tabular}{llll}
\hline \multicolumn{1}{c}{ Variabel } & Sig. & Korelasi Pearson Product Moment & Hasil \\
\hline $\begin{array}{l}\text { Impulsive Buying } \\
\text { Celebrity Worship }\end{array}$ & 0.000 & 0.520 & H diterima \\
\hline
\end{tabular}

Berdasarkan uji korelasi disimpulkan bahwa skor impulsive buying memiliki hubungan positif yang signifikan $(\mathrm{p}<0,05)$ dengan skor celebrity worship, artinya semakin tinggi skor celebrity worship subjek, maka semakin tinggi pula kecenderungan impulsive buying nya (tabel 3).

Tabel 4 Hasil Uji Hipotesis Regresi Sederhana

Coefficients $^{\mathrm{a}}$

\begin{tabular}{|c|c|c|c|c|c|c|}
\hline & \multirow[t]{2}{*}{ Model } & \multicolumn{2}{|c|}{ Unstandardized Coefficients } & \multirow{2}{*}{$\begin{array}{c}\text { Standardized } \\
\text { Coefficients } \\
\text { Beta } \\
\end{array}$} & \multirow[t]{2}{*}{$\mathbf{t}$} & \multirow[t]{2}{*}{ Sig. } \\
\hline & & B & Std. Error & & & \\
\hline \multirow{2}{*}{1} & (Constant) & 4.069 & 2.467 & & 1.650 & .100 \\
\hline & Celebrity & .356 & .033 & .527 & 10.765 & .000 \\
\hline
\end{tabular}

a. Dependent Variable: Impulsive

Berdasarkan nilai signifikansi dari tabel coefficients, diperoleh nilai signifikansi sebesar 0,000 <0,05 sehingga dapat disimpulkan bahwa celebrity worship berpengaruh terhadap impulsive buying. Nilai constant (a) diketahui sebesar 4,069 sedangkan nilai celebrity worship (b/koefisien regresi) sebesar 0,527 (tabel 4). Berdasarkan nilai constant (a) dan koefisien regresi (b) tersebut dapat dibuat persamaan regresi sebagai berikut:

$$
\begin{aligned}
& Y=a+b X \\
& Y=4,069+0,527 X
\end{aligned}
$$

Berdasarkan persamaan di atas, dapat disimpulkan bahwa:

a. Konstanta sebesar 4,069 mengandung arti bahwa nilai konsistensi variabel partisipasi adalah sebesar 4,069.

b. Koefisien regresi $X$ sebesar 0,527 yang berarti setiap penambahan $1 \%$ nilai celebrity worship maka nilai partisipasi bertambah 0,527 . Koefisien regresi tersebut bernilai positif sehingga dapat dikatakan bahwa arah pengaruh celebrity worship terhadap impulsive buying adalah positif. 
Koefisien determinasi $\left(\mathrm{R}^{2}\right)$ yaitu bagian dari keragaman total variabel terikat (variabel dependen) yang dapat diperhitungkan oleh keragaman variabel bebas (variabel independen). Besarnya koefisien determinasi dapat dilihat pada adjusted $r$ square yang dinyatakan dalam persentase.

Tabel 5 Koefisien Determinasi $\left(\mathrm{R}^{2}\right)$

Model Summary

\begin{tabular}{lllll} 
Model & $\mathbf{R}$ & R Square & $\begin{array}{l}\text { Adjusted } \\
\text { Square }\end{array}$ & $\begin{array}{l}\text { R } \\
\text { Estimate }\end{array}$ \\
\hline 1 & $.527^{\mathrm{a}}$ & 0.278 & 0.276 & 5.88236 \\
\hline
\end{tabular}

a. Predictors: (Constans), $\mathrm{X}$

Berdasarkan tabel 5 didapatkan hasil berupa pengaruh celebrity worship terhadap impulsive buying merchandise idola pada remaja penggemar BTS dengan nilai $\mathrm{R}=0,527$ dan jumlah persentase yang didapatkan adalah $\mathrm{R}^{2}=0,278$. Nilai $\mathrm{R}^{2}$ dapat diartikan bahwa celebrity worship memiliki pengaruh terhadap impulsive buying pada merchandise idola sebesar $27,8 \%$, sisanya sebesar $72,2 \%$ dari impulsive buying terhadap merchandise idola dipengaruhi oleh variabel lainnya.

Peneliti juga melakukan analisa pembelian impulsif terhadap kelompok subjek dan diperoleh hasil sebagai berikut :

Tabel 6 Hasil Uji Analysis of Variance Impulsive Buying berdasarkan Tahap Perkembangan Remaja dan Durasi Menggemari BTS

\begin{tabular}{|c|c|c|c|c|c|c|c|}
\hline Kategori Usia & $\mathbf{n}$ & Mean & Sig. & Kategori Durasi & $\mathbf{n}$ & Mean & Sig. \\
\hline Remaja Awal & 96 & 30,66 & \multirow{3}{*}{0,275} & 1-2 tahun & 170 & 29.91 & \multirow{3}{*}{0,180} \\
\hline Remaja Tengah & 115 & 29,58 & & 3-4 tahun & 113 & 31.29 & \\
\hline Remaja Akhir & 92 & 31,07 & & $\geq 5$ tahun & 20 & 29.10 & \\
\hline
\end{tabular}

Berdasarkan hasil uji Anova tersebut $(p>0,05)$ dapat disimpulkan bahwa tidak ada perbedaan pembelian impulsif pada kelompok subjek yang berbeda tahapan usia perkembangan remajanya, ataupun pada kelompok subjek yang berbeda durasi lamanya menggemari BTS. Artinya, kelompok usia dan durasi menggemari BTS tidak mempengaruhi kecenderungan pembelian impulsif yang ditunjukkan oleh subjek (tabel 6).

Peneliti melakukan uji korelasi terhadap aspek-aspek yang terdapat pada celebrity worship dengan aspek-aspek yang terdapat pada impulsif buying. Tujuannya adalah untuk mengetahui aspek variabel bebas (celebrity worship) manakah yang berpengaruh kuat terhadap variabel terikat (impulsif buying).

Tabel 7 Matriks Korelasi Celebrity Worship terhadap Impulsive Buying

Impulsive Buying (Y)

\begin{tabular}{|c|c|c|c|c|}
\hline \multirow{4}{*}{$\begin{array}{l}\text { Celebrity } \\
\text { Worship } \\
\text { (X) }\end{array}$} & Aspek & Kognitif (Y1) & Afektif (Y2) & $\begin{array}{c}\text { Total Skor } \\
\text { (Y1\&Y2) }\end{array}$ \\
\hline & Entertainment Social (X1) & $\begin{array}{l}r=\mathbf{0 , 1 7 1} \\
p=0,003\end{array}$ & $\begin{array}{l}r=0,422 \\
p=0,000\end{array}$ & $\begin{array}{l}r=0,330^{*} \\
p=0,000\end{array}$ \\
\hline & Intense Personal Feeling (X2) & $\begin{array}{l}r=0,381 \\
p=0,000\end{array}$ & $\begin{array}{l}r=0,628^{* *} \\
p=0,000\end{array}$ & 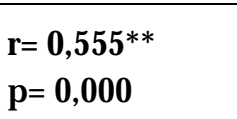 \\
\hline & Borderline Pathological (X3) & $\begin{array}{l}r=0,302 \\
p=0,000\end{array}$ & $\begin{array}{l}r=0,440 \\
p=0,000\end{array}$ & $\begin{array}{l}r=0,406 \\
p=0,000\end{array}$ \\
\hline
\end{tabular}

*) Korelasi paling rendah

*) Korelasi paling kuat 
Berdasarkan hasil uji matriks korelasi, dapat diketahui bahwa aspek intense personal feeling pada celebrity worship memiliki nilai koefisien tertinggi pada keseluruhan aspek impulsive buying yaitu sebesar 0,555. Ini dapat diartikan bahwa intense personal feeling memiliki pengaruh paling besar terhadap pemicu terjadinya impulsive buying merchandise idola pada remaja penggemar BTS (tabel 7).

\section{Pembahasan}

Penelitian ini dilakukan dengan dilatar belakangi oleh munculnya fenomena impulsive buying pada remaja yang menggemari grup idola BTS (ARMY). Pembelian impulsif yang dilakukan oleh remaja penggemar grup BTS terjadi pada merchandise-merchandise yang berhubungan dengan BTS seperti album musik, light-stick, photocard, dan lain-lain. Fenomena ini didapatkan oleh peneliti melalui studi awal yang berupa observasi dan wawancara terhadap 10 anggota fanbase BTS di aplikasi Line dan media sosial Twitter. Hasil studi awal, baik melalui observasi maupun wawancara, menunjukan bahwa 10 orang responden studi awal memiliki kecenderungan untuk melakukan pembelian yang impulsif terhadap merchandise BTS.

Hasil penemuan di studi awal dibuktikan dengan hasil penelitian terhadap 303 subjek penelitian yang menunjukan bahwa terdapat korelasi antara celebrity worship dengan impulsive buying terhadap merchandise BTS dengan nilai signifikansi sebesar $\mathrm{p} \leq 0,05$ dengan arah hubungan yang positif sehingga dapat diartikan bahwa semakin tinggi celebrity worship maka akan semakin tinggi kecenderungan impulsive buying terhadap merchandise BTS, dan juga sebaliknya apabila tingkat celebrity worship rendah maka semakin rendah pula impulsive buying terhadap merchandise BTS.

Berdasarkan hasil uji hipotesis, perhitungan statistik menunjukan bahwa hasil hipotesis diterima dengan nilai $\mathrm{p} \leq 0,05$. Besarnya pengaruh celebrity worship terhadap impulsive buying pada merchandise BTS yaitu sebesar $27,8 \%$ dengan arah pengaruh yang positif. Hasil dari perhitungan juga terlihat bahwa nilai konsisten variabel partisipasi sebesar 4,069 dan konstanta sebesar 0,527.

Matriks korelasi antar aspek menunjukan bahwa aspek intense personal feeling memiliki pengaruh yang paling tinggi terhadap impulsive buying sebesar 0,555 dan juga mempengaruhi aspek afektif pada impulsive buying sebesar 0,628. Menurut Maltby dkk (2004), intense personal feeling adalah sebuah perasaan yang membuat penggemar merasa bahwa dirinya memiliki suatu hubungan personal yang kuat dan merasa dekat dengan selebriri idola sehingga dapat disimpulkan bahwa perasaan yang kuat dan dekat terhadap BTS mempengaruhi responden untuk melakukan pembelian yang impulsif terhadap barang-barang yang berkaitan dengan BTS. Hal ini berkesesuaian dengan penelitian yang dilakukan oleh Pertiwi (2013) bahwa kecintaan seorang penggemar terhadap selebriti idolanya dapat membuat penggemar rela melakukan apapun termasuk menghabiskan uang untuk membeli merchandise idola.

Hasil uji analisis tambahan sosio-demografi menggambarkan bahwa remaja akhir memiliki skor mean impulsive buying sebesar 31,07 yang mana lebih tinggi dibanding remaja awal dan remaja tengah. Hal ini bisa dikarenakan usia remaja akhir yang mayoritas sudah lulus dari sekolah mulai mendapatkan pemasukan yang lebih besar, seperti telah bekerja atau uang saku yang lebih besar daripada saat masih bersekolah sehingga responden remaja akhir memiliki potensi untuk melakukan pembelian yang lebih besar daripada responden remaja awal dan remaja tengah yang masih bersekolah.

Masih berdasarkan tahapan perkembangan remaja, pada celebrity worship besarnya skor mean menurun seiring bertambahnya tahapan perkembangan. Remaja awal memiliki skor mean paling tinggi sebesar 75,90 dan remaja akhir memiliki skor paling rendah dengan nilai 72,90. Ini sesuai dengan teori Maltby dan McCutcheon (2004) yang menyatakan bahwa seiring dengan bertambahnya usia maka celebrity worship akan semakin berkurang, ini dikarenakan remaja akhir yang akan segera masuk ke fase 
dewasa awal mulai merubah arah ketertarikannya terhadap selebriti idola, sehingga celebrity worship pada remaja cenderung lebih banyak terjadi pada remaja awal daripada remaja akhir.

Berdasarkan lamanya seorang responden menggemari BTS, responden yang telah menggemari BTS selama 3 - 4 tahun memiliki memiliki skor mean paling tinggi yaitu sebesar 31,29 terhadap impulsive buying pada merchandise BTS, sedangkan pada celebrity worship responden yang telah menggemari BTS selama lebih dari 5 tahun terlihat memiliki skor mean yang paling tinggi sehingga dapat disimpulkan bahwa semakin lama seorang penggemar menggemari BTS maka semakin besar kemungkinan celebrity worship yang terjadi.

Melihat keseluruhan hasil penelitian, secara garis besar dapat disimpulkan bahwa celebrity worship memiliki pengaruh sebesar $27,8 \%$ terhadap impulsive buying merchandise BTS pada remaja yang menggemari grup idola BTS. Aspek yang paling mempengaruhi adalah intense personal feeling, dimana perasaan yang intens dan kuat terhadap BTS memicu terjadinya pembelian yang impulsif terhadap merchandise BTS. Penelitian ini mendukung teori Maltby dan McCutcheon (2004) yang menyatakan bahwa semakin bertambahnya usia maka celebrity worship akan semakin berkurang. Hal ini ditunjukan dengan analisis uji tambahan sosio-demografi berdasarkan tahap perkembangan remaja dimana nilai mean tertinggi didapat oleh remaja awal dan nilai mean terendah oleh remaja akhir.

Berdasarkan hasil uji hipotesis, perhitungan statistik menunjukan bahwa hasil hipotesis diterima dengan nilai $p<0,05$. Besarnya pengaruh celebrity worship terhadap impulsive buying pada merchandise BTS yaitu sebesar $27,8 \%$ dengan arah pengaruh yang positif. Hasil ini menunjukkan bahwa celebrity worship berpengaruh sebesar $27,8 \%$ terhadap kemunculan kecenderungan perilaku pembelian impulsif (impulsive buying) pada penggemar grup idola BTS yang menjadi subjek penelitian, sementara sisanya yang lain yaitu sebesar 72,2\% pembelian impulsif subjek dipengaruhi oleh faktor-faktor lainnya. Berdasarkan hasil analisa tambahan yang dilakukan, diketahui bahwa usia subjek dan lamanya durasi menggemari grup idola BTS tidak berpengaruh terhadap kecenderungan pembelian impulsifnya.

\section{Kesimpulan dan Rekomendasi}

Berdasarkan hasil penelitian ini, maka dapat diambil kesimpulan bahwa terdapat hubungan yang signifikan dan positif antara celebrity worship dengan impulsive buying pada remaja penggemar grup idola BTS. Celebrity worship berpengaruh secara signifikan terhadap pembelian merchandise idola secara impulsif pada remaja penggemar grup idola BTS. Berdasarkan matriks korelasi antar aspek, diketahui bahwa aspek intense personal feeling pada celebrity worship paling mempengaruhi aspek afektif pada impulsive buying.

Berdasarkan hasil analisa dalam penelitian ini, disarankan kepada responden penelitian, untuk dapat mengidentifikasi kecenderungan celebrity worship yang mungkin dimiliki demi mencegah terjadinya dampak dari celebrity worship, di penelitian ini khususnya dalam bentuk perilaku belanja yang abnormal. Peneliti juga menyarankan agar subjek penelitian lebih mempertimbangkan aspek kognitif seperti pertimbangan harga dan kegunaan produk sebelum membeli produk merchandise idola. Bagi masyarakat, peneliti menyarankan untuk lebih bijaksana dalam menggemari selebriti sehingga dapat menghindari terjadinya celebrity worship dan impulsive buying terhadap merchandise yang seakan menjadi suatu keharusan untuk dibeli oleh para penggemar. Bagi peneliti selanjutnya, peneliti menyarankan agar melakukan penelitian lanjutan dengan menggunakan subjek ARMY usia dewasa awal untuk melihat apakah celebrity worship benar mempengaruhi impulsive buying pada merchandise BTS di segala usia. Penelitian selanjutnya juga bisa dilakukan pada fandom grup idola lain selain BTS, sehingga dapat dilihat apakah celebrity worship benar mempengaruhi impulsive buying 
terhadap merchandise idola secara umum. Bagi pebisnis di bidang merchandise idola, peneliti menyarankan agar lebih kreatif dalam mengaplikasikan ide pada barang-barang yang lebih memiliki nilai guna sehingga merchandise yang dibeli bisa digunakan menjadi sesuatu yang lebih berarti. Saran lainnya agar penjual tetap up-to-date terhadap dunia hiburan sehingga dapat mengikuti trend bintang idola mana yang tengah populer di kalangan calon pembeli.

\section{Daftar Pustaka}

Coley, A., \& Burgess, B. (2003). Gender differences in cognitive and affective impulse buying. Journal of fashion markting and management an international journal, 7(3).

Darfianti, D., Bagus Ani Putra, M. G. (2010). Pemujaan terhadap idola pop sebagai dasar intimate relationship pada dewasa awal: sebuah studi kasus. Jurnal Psikologi Kepribadian dan Sosial. 1(2), 53-560.

Frederika. A., Suprapto, M. H., Tanojo, K. L. (2015). Hubungan antara harga diri dan konformitas dengan celebrity worship pada remaja di Surabaya. Jurnal Gema Aktualita. 4(1), 61-69.

Ghozali, I. (2013). Aplikasi Analisis Multivariat dengan Program IBM SPSS (7 ed.). Semarang: Universitas Diponegoro.

Herabadi, A. G., Verplanken, B., \& Knippenberg, A. V. (2009). Consumption experience of impulse buying in Indonesia: Emotional arousal and hedonistic considerations. Asian Journal of Social Psychology, 12(1), 20-31.

Jung, Jae Hee., Hwang, Choon Sup. (2016). Associations Between Attitudes Toward Cosmetic Surgery, Celebrity Worship, and Body Image Among South Korean and US Female College Students. Fashion and Textiles, 3, 17. https://doi.org/10.1186/s40691-016-0069-6

Liu, J. K. K. (2013). Idol worship, religiosity, and self-esteem among university and secondary students in Hong Kong. Discovery - SS Student E-Journal, 2, 15-28.

Maltby, J., Houran, J., dan McCutcheon, L.E. (2003). A Clinical Interpretation Of Attitudes and Behaviors Associated with Celebrity Worship. The journal of Nervous and Mental Disease. vol. 191, no. 1, hal. 25-29.

Maltby, J., Day, L., McCutcheon, L. E., Gillett, R., Houran, J., Ashe, D. D. (2004). Personality and coping: A context for examining celebrity worship and mental health. British Journal of Psychology. 95, 411-428.

Maltby, J., Giles, D. C., Barber. L., McCutcheon, L. E. (2005). Intense-personal celebrity worship and body image: Evidence of a link among female adolescents. British Journal of Health Psychology. 10, 17-32.

Maltby, J., McCutcheon, L. E., Ashe, D. D., Houran, J. (2001). The Self-Reported Psychological Well-Being of Celebrity Worshippers. North American Journal of Psychology. 3, 441-452.

McCutcheon, L. E. (2003). Machiavellianism, belief in a just world, and the tendency to worship celebrities. Current Research in Social Psychology, 8(9), 131-139.

McCutcheon, L.E., Lange, R. and Houran, J. (2002), Conceptualization and measurement of celebrity worship. British Journal of Psychology, 93: 67-87. https://doi.org/10.1348/000712602162454

North, A. C., Sheridan, L., Maltby, J., Gillett, R. (2007). Attribution Style, Self-steem, and Celebrity Worship. Journal of Media Psychology. 9, 291-308.

Papalia, D.E., Old, S.W., Feldman, R.D. (2008). Human Development (Psikologi Perkembangan). Jakarta : Kencana.

Pemayun, T., \& Ekawati, N. (2016). Pengaruh Promosi, Atmosfer Gerai, dan Merchandise Terhadap Pembelian Impulsif Pada Hardy's Mall Gatsu Denpasar. E-Jurnal Manajemen, 5(7). Retrieved from https://ojs.unud.ac.id/index.php/Manajemen/article/view/20674

Rook, D. W. (1987). The Buying Impulse. Journal of Consumer Research, 14(2), 189-199.

Sella, A. P. (2013). Konformitas dan fanatisme pada remaja korean wave (penelitian komunitas super junior fan club elf "ever lasting friend") di Samarinda. Ejournal.Psikologi.Fisip-Unmul, 157-166 
Sheridan, L., North, A., Maltby, J., Gillett, R. (2007). Celebrity worship, addiction and criminality. Psychology, Crime $\mathcal{E}$ Law. 13(6): 559-571.

Swami, V., Chamorro-Premuzic, T., Mastor, K., Siran, F.H., Mohsein, M., Said, M., Jaafar, J.L., Sinniah, D. and Pillai, S.K. (2011). Celebrity worship among university students in Malaysia: a methodological contribution to the celebrity attitude scale. European Psychologist, 16(4), 334-342.

Verplanken, B. and Herabadi, A. (2001), Individual differences in impulse buying tendency: feeling and no thinking. Eur. J. Pers., 15: S71-S83. https://doi.org/10.1002/per.423 